\title{
Mutagenic consequences of cytosine alterations site-specifically embedded in the human genome
}

\author{
Akira Sassa $^{1 * \dagger}$, Yuki Kanemaru ${ }^{1,2 \dagger}$, Nagisa Kamoshita ${ }^{1}$, Masamitsu Honma ${ }^{1}$ and Manabu Yasui ${ }^{*}$
}

\begin{abstract}
Introduction: Cytosine residues in $\mathrm{CpG}$ dinucleotides often undergo various types of modification, such as methylation, deamination, and halogenation. These types of modifications can be pro-mutagenic and can contribute to the formation of mutational hotspots in cells. To analyze mutations induced by DNA modifications in the human genome, we recently developed a system for tracing DNA adducts in targeted mutagenesis (TATAM). In this system, a modified/damaged base is site-specifically introduced into intron 4 of thymidine kinase genes in human lymphoblastoid cells. To further the understanding of the mutagenesis of cytosine modification, we directly introduced different types of altered cytosine residues into the genome and investigated their genomic consequences using the TATAM system.

Findings: In the genome, the pairing of thymine and 5-bromouracil with guanine, resulting from the deamination of 5-methylcytosine and 5-bromocytosine, respectively, was highly pro-mutagenic compared with the pairing of uracil with guanine, resulting from the deamination of cytosine residues.
\end{abstract}

Conclusions: The deamination of 5-methylcytosine and 5-bromocytosine rather than that of normal cytosine dramatically enhances the mutagenic potential in the human genome.

Keywords: Mutagenesis, Gene targeting, Deamination, Mutagenic potential

\section{Introduction}

CpG dinucleotides in the genome are subjected to various types of modification including cytosine methylation. The methylation of cytosine to 5-methylcytosine $(5-\mathrm{mC})$ is a common DNA modification and is important for the epigenetic mechanism of gene regulation in higher eukaryotes. In mammalian cells, 3-6\% of cytosine residues and $70-80 \%$ of cytosine residues in CpG dinucleotides are methylated [1-3]. Such cytosine residues often undergo inappropriate modifications (Fig. 1a), leading to genomic instability.

Cytosine and 5-mC in the genome are often spontaneously deaminated to form U:G and T:G mismatches, respectively [4]. These mismatches are also produced by enzymatic deamination caused by activation-induced

\footnotetext{
* Correspondence: a-sassa@nihs.go.jp; m-yasui@nihs.go.jp

${ }^{\dagger}$ Equal contributors

'Division of Genetics and Mutagenesis, National Institute of Health Sciences,

1-18-1 Kamiyoga, Setagaya-ku, Tokyo 158-8501, Japan

Full list of author information is available at the end of the article
}

deaminase or apolipoprotein B mRNA editing enzyme, catalytic polypeptide-like 3A (APOBEC3A) [5-7]. The resultant uracil and thymine can pair with adenine during DNA replication, causing C:G to T:A transition mutations. In fact, cytosine residues at $\mathrm{CpG}$ dinucleotides in the tumor suppressor gene TP53 is known as a mutational hotspot in carcinoma cells [8]. It has been suggested that in DNA, the hydrolytic deamination of 5-mC occurs more rapidly than that of cytosine $[9,10]$.

Cytosine modification also occurs during chronic inflammation. At inflammation sites, phagocytic cells generate peroxidases that produce reactive oxidants such as hypobromous acid and hypochlorous acid [11-13]. These oxidants can result in several types of halogenated DNA damages, leading to mutagenesis [14-20]. Among them, the halogenation of cytosine is detrimental to organisms. For example, 5-bromocytosine (5-BrC) and 5-chlorocytosine (5-ClC) in DNA can potentially compromise epigenetic signals by mimicking $5-\mathrm{mC}$ [21]. Moreover, 5 -BrC is converted 
A<smiles>Cc1cn(C)c(=O)nc1N</smiles>

B

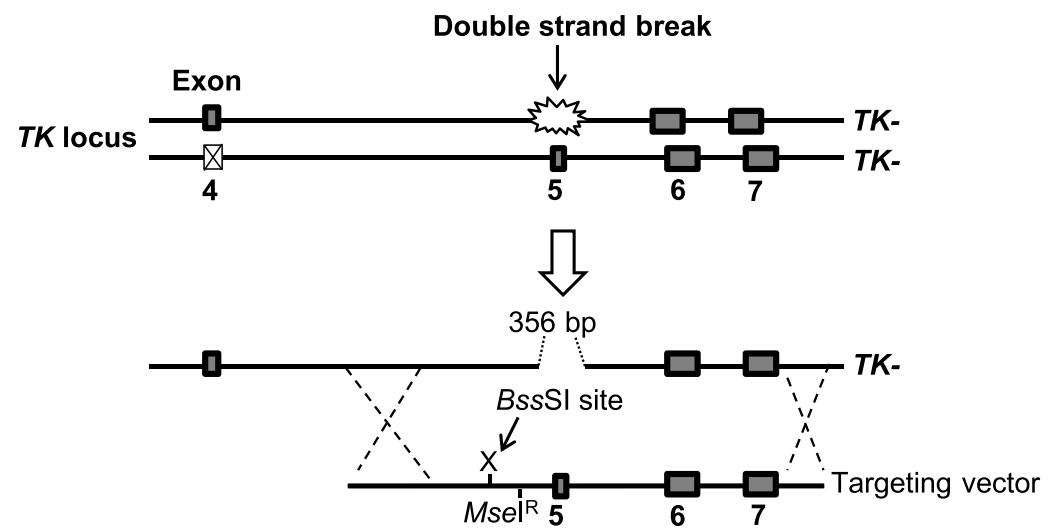

Homologous recombination with the targeting vector
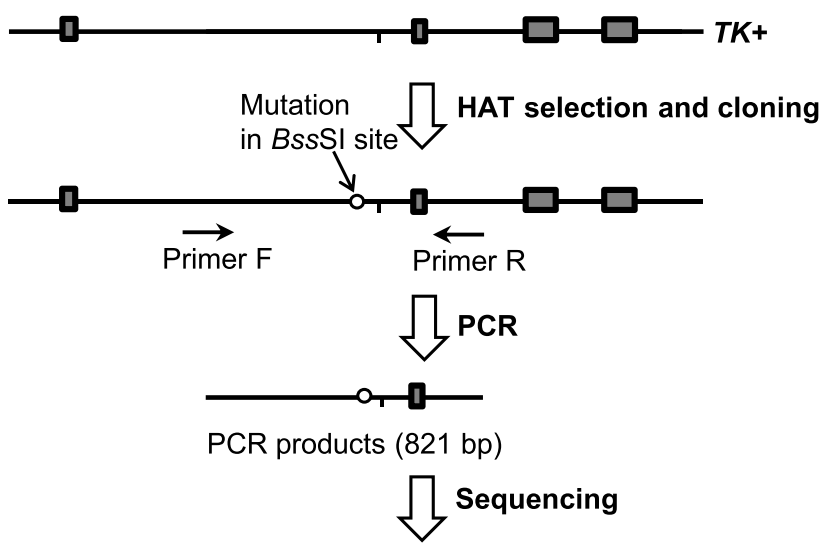

Determination of

Mutation frequency and

Spectrum of modified base

Fig. 1 Overview of the TATAM system. Structures of cytosine alteration (a) and the principle of the TATAM system (b). X on the targeting vector

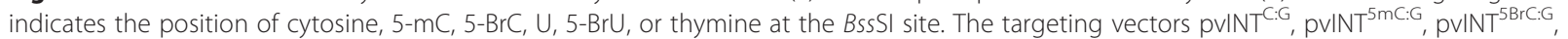
pvINT $T^{\mathrm{U}: G}$, pvINT $^{\text {SBrU:G}}$, or pvINT ${ }^{\mathrm{T}: G}$ and the I-Scel expression plasmid pCBASce were co-transfected into TSCER122 cells. Double-strand break at the I-Scel site enabled gene targeting by inducing site-specific homologous recombination. The targeting vector contained an Msel ${ }^{R}$ site that was resistant to Msel digestion and thereby distinguished targeted and non-targeted revertants of TK. TK revertants were selected by using HAT. Genomic DNA of the revertant colonies was prepared, and part of the TK gene containing the modified DNA integrated site was amplified by PCR.

The amplified fragment was sequenced as described in the Materials and Methods section

to 5-bromouracil (5-BrU) by APOBEC3A [22], which may result in enhanced mutagenesis in the genome.

The mutagenesis of modified/deaminated cytosine residues has been extensively studied in Escherichia coli and in plasmids introduced into mammalian cells [4, 10, 23-27].
However, the mutagenic consequences of such alterations in the human genome are yet to be completely understood. We recently developed a system for tracing DNA adducts in targeted mutagenesis (TATAM) by directly introducing a DNA modification site specifically into intron 4 of the 
thymidine kinase (TK) gene in human lymphoblastoid cells (Fig. 1b) [28]. In this study, for better understanding the mutagenesis of cytosine modification in vivo, we introduced cytosine, $5-\mathrm{mC}$, and $5-\mathrm{BrC}$ paired with guanine and their deamination products $\mathrm{U}: \mathrm{G}, \mathrm{T}: \mathrm{G}$, and $5-\mathrm{BrU}: \mathrm{G}$ mismatch at $\mathrm{CpG}$ dinucleotides in the genome using the TATAM system.

\section{Materials and methods}

\section{Cell culture}

The human lymphoblastoid TSCER122 cells used were derivatives of TK6 cells, as reported previously [28]. Cells were maintained in RPMI 1640 medium (Nacalai Tesque) supplemented with $10 \%$ horse serum (JRH Biosciences), $200 \mu \mathrm{g} / \mathrm{ml}$ of sodium pyruvate, $100 \mathrm{U} / \mathrm{ml}$ of penicillin, and $100 \mu \mathrm{g} / \mathrm{ml}$ of streptomycin at $37{ }^{\circ} \mathrm{C}$ under $5 \% \mathrm{CO}_{2}$ and $100 \%$ humidity.

\section{Outline of the TATAM system}

TSCER122 cells are compound heterozygous for the TK gene $(T K-/-)$ because of the complete loss of exon 5 in one allele and a point mutation in exon 4 in the other (Fig. 1b). Because there is an I-SceI recognition site in the original exon 5 region, the expression of the I-SceI enzyme in TSCER122 cells generated a double-strand break in the $T K$ gene, allowing for the generation of the wild type $T K(T K+/-)$ by homologous recombination with the targeting vector. TSCER122 cells were cotransfected with the I-SceI expression plasmid and the targeting vector site-specifically containing a synthetic DNA adduct. After 3 days incubation, cells were seeded 96-well plates in the presence of hypoxanthine, aminopterin, and thymidine (HAT) to isolate the DNA adductintegrated revertant clones. Subsequently, the TK gene loci of the revertant clones were sequenced (Fig. 1b).

\section{Preparation of site-specific modified targeting vector} The targeting vectors pvINT ${ }^{\mathrm{C}: \mathrm{G}}$, pvINT $^{5 \mathrm{mC}: \mathrm{G}}$, pvINT $^{5 \mathrm{BrC}: \mathrm{G}}$, pvINT $^{\mathrm{U}: \mathrm{G}}$, pvINT ${ }^{5 \mathrm{BrU}: \mathrm{G}}$, and pvINT $^{\mathrm{T}: \mathrm{G}}$ containing $\mathrm{C}: \mathrm{G}$, 5-mC:G, 5-BrC:G, U:G, 5-BrU:G, and T:G base pairs, respectively, in place of the underlined cytosine/guanine at the BssSI site (5'-CTCGTG/5' -CACGAG) were prepared by a polymerase chain reaction (PCR)-based method with the plasmid pTK15, as previously described (Fig. 2) $[28,29]$. A $5^{\prime}$-TTCA sequence $\left(M s e \mathrm{I}^{\mathrm{R}}\right)$ was labeled near the modified BssSI site. This modified site was resistant to MseI digestion and thus distinguished targeted and non-targeted revertants of $T K$ according to an interallelic recombination (Fig. 1b). The vectors were sequenced to confirm the presence of the modified cytosine at the expected site.

\section{Transfection and cloning of TK revertant cells}

DNA transfection was performed as previously described [28]. Briefly, the targeting vector $(1 \mu \mathrm{g})$ and I-SceI expression plasmid pCBASce $(50 \mu \mathrm{g})$ were co-transfected into $5 \times 10^{6}$ cells that were suspended in $0.1 \mathrm{ml}$ of Nucleofector Solution V (Lonza) using Nucleofector I, in accordance with the manufacturer's instructions. After incubation for $72 \mathrm{~h}$, cells were seeded into 96-microwell plates in the presence of HAT (200 $\mu \mathrm{M}$ hypoxanthine, $0.1 \mu \mathrm{M}$ aminopterin, and 17.5 $\mu \mathrm{M}$ thymidine) for isolating targeting vector-integrated revertant clones. After incubation for 2 weeks, drug-resistant colonies (TK revertants) were analyzed.

\section{Mutation analysis}

Genomic DNA templates for PCR were prepared from TK-revertant colonies using alkaline lysis, as previously described [30]. Briefly, cells were treated with $18 \mu \mathrm{l}$ of $50 \mathrm{mM} \mathrm{NaOH}$ at $95{ }^{\circ} \mathrm{C}$ for $10 \mathrm{~min}$ and neutralized by adding $2 \mu \mathrm{l}$ of $1 \mathrm{M}$ Tris- $\mathrm{HCl}(\mathrm{pH} 8.0)$. The cell lysates were then used as templates for PCR to amplify the $T K$ gene fragments containing the modified cytosine integration site. PCR was performed using KOD FX (Toyobo) with the following primers: forward primer 5'-GCT CTT ACG GAA AAG GAA ACA GG-3' and reverse primer $5^{\prime}$-CTG ATT CAC AAG CAC TGA AG3 '. The resulting DNA fragments were sequenced using an ABI 3730 $\times 1$ DNA analyzer (Applied Biosystems), and clones harboring the $M s e \mathrm{I}^{\mathrm{R}}$ sequence were counted for determining the frequency of modified cytosine integration and numbers of mutations at the BssSI site. The integration frequency of the modified cytosine was calculated by

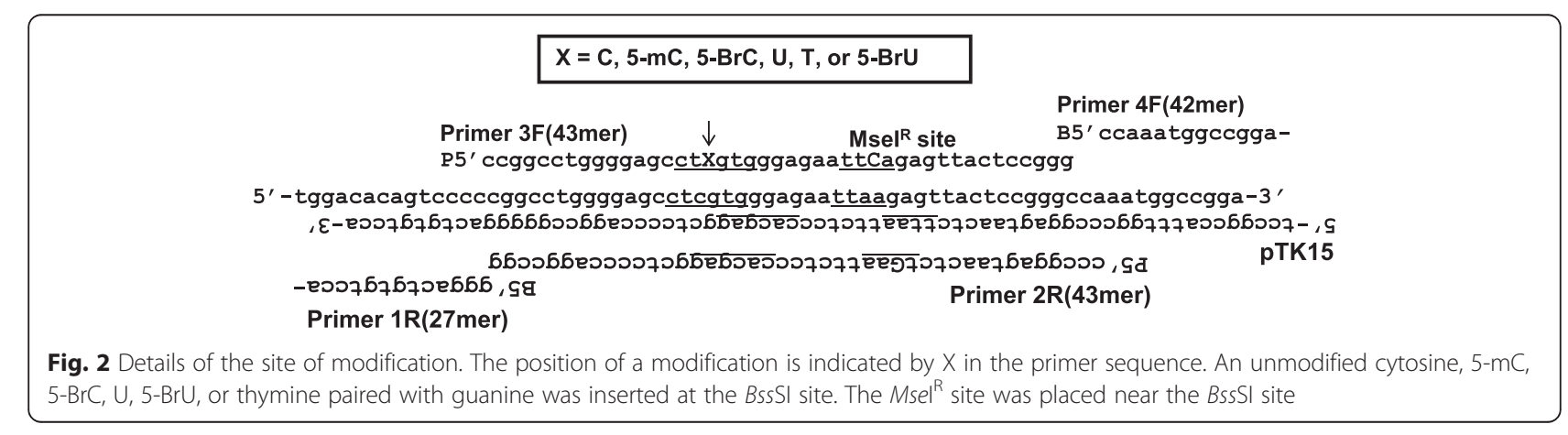


dividing the number of $M s e \mathrm{I}^{\mathrm{R}}$ clones by the total number of revertant clones analyzed. A single point mutation was defined as a single base substitution, insertion, or deletion detected at the modified cytosine. Multiple mutations were multiple base substitutions, deletions, and/or insertions that were detected at sites including the modified cytosine. Base substitutions, deletions, and/or insertions found at sites other than the modified cytosine were defined as non-targeted. Mutant proportions were calculated by dividing the number of mutants by the number of $M s e \mathrm{I}^{\mathrm{R}}$-bearing clones.

\section{Statistical analysis}

Statistical significance was evaluated by Fisher's exact test. $P$-values less than 0.01 were considered to be statistically significant.

\section{Results and discussion}

To investigate the mutagenic potential of cytosine alterations in the genome, targeting vectors pvINT $^{\mathrm{C}: \mathrm{G}}$, pvINT $^{5 \mathrm{mC:G}}$, pvINT ${ }^{5 \mathrm{BrC}: \mathrm{G}}$, pvINT $^{\mathrm{U}: \mathrm{G}}$, pvINT $^{5 \mathrm{BrU}: \mathrm{G}}$, and pvINT $^{\mathrm{T}: \mathrm{G}}$ were prepared, containing C:G, 5-mC:G, 5BrC:G, U:G, 5-BrU:G, and T:G base pairs, respectively, as previously reported [28]. The revertant frequencies were comparable between the targeting vectors used (data not shown), indicating that the modified residues on the targeting vector did not influence the efficiency of homologous recombination.

\section{Mutagenic potential of 5-methylcytosine and 5-bromocytosine in the genome}

As shown in Table 1, the total proportion of mutants induced by the integration of pvINT ${ }^{\mathrm{C}: \mathrm{G}}$, the control vector, was $1.5 \%$; no C:G to T:A transition mutations were observed (Fig. 3). When pvINT ${ }^{5 \mathrm{mC}: \mathrm{G}}$ was integrated, the proportion of mutants $(1.4 \%)$ was comparable to that of

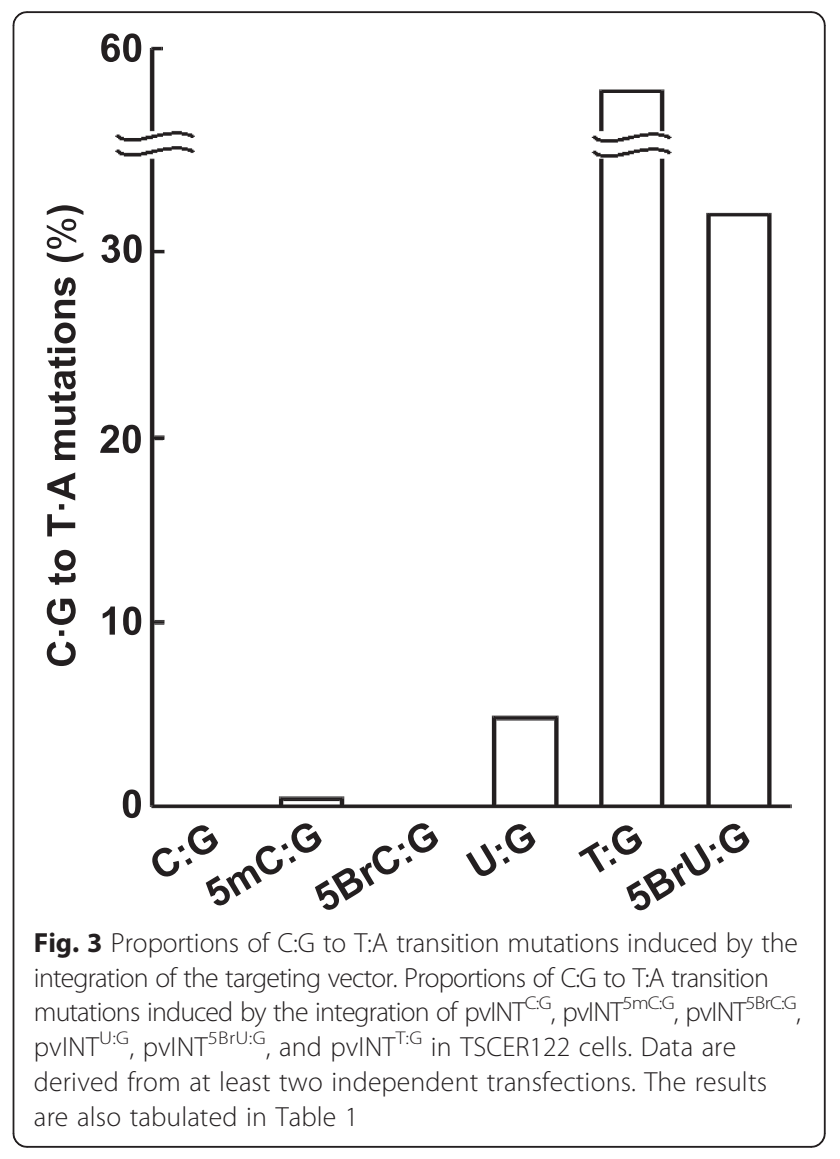

pvINT $^{\mathrm{C}: G}$. Some C:G to T:A transition mutations $(0.44 \%)$ were detected, followed by one base deletion $(0.20 \%)$, one base insertion $(0.20 \%)$, and non-targeted mutations, referred to as "others" (0.59\%), indicating that 5-mC itself enhances C:G to T:A transition mutations via its deamination, but the frequency is below that of background mutations in this system. This is in agreement with the

Table 1 Mutation spectra induced by integration of the targeting vectors

\begin{tabular}{|c|c|c|c|c|c|c|c|c|c|c|c|c|}
\hline \multirow{2}{*}{$\begin{array}{l}\text { Targeting } \\
\text { vector }\end{array}$} & \multirow{2}{*}{$\begin{array}{l}\text { TK } \\
\text { revertants } \\
\text { analyzed }\end{array}$} & \multirow{2}{*}{$\begin{array}{l}\text { X:G- } \\
\text { integrated } \\
\text { revertants }^{a}\end{array}$} & \multirow{2}{*}{$\begin{array}{l}\text { No } \\
\text { mutation }\end{array}$} & \multicolumn{5}{|c|}{ Single point mutation ${ }^{b}$} & \multirow[t]{2}{*}{ Multiple $^{\mathrm{e}}$} & \multirow[t]{2}{*}{ Others $^{f}$} & \multirow{2}{*}{$\begin{array}{l}\text { Total } \\
\text { mutation }\end{array}$} & \multirow[t]{2}{*}{$N D^{9}$} \\
\hline & & & & $\overline{\mathrm{T}}$ & $\mathrm{G}$ & A & $\mathrm{Del}^{\mathrm{C}}$ & $\operatorname{lns}{ }^{d}$ & & & & \\
\hline $\mathrm{pvINT}^{\mathrm{C}: \mathrm{G}}$ & 457 & 410 (100\%) & $403(98 \%)$ & 0 & 0 & 0 & $2(0.49 \%)$ & $1(0.24 \%)$ & 0 & $3(0.73 \%)$ & $6(1.5 \%)$ & 1 \\
\hline $\mathrm{pvINT}^{5 \mathrm{mC}: \mathrm{G}}$ & 722 & $676(100 \%)$ & $667(99 \%)$ & $3(0.44 \%)$ & 0 & 0 & $1(0.20 \%)$ & $1(0.20 \%)$ & 0 & $4(0.59 \%)$ & $9(1.4 \%)$ & 0 \\
\hline $\mathrm{pvINT}^{5 \mathrm{BrC:G}}$ & 778 & $705(100 \%)$ & 700 (99 \%) & 0 & $2(0.28 \%)$ & 0 & 0 & 0 & 0 & $3(0.43 \%)$ & $5(0.71 \%)$ & 3 \\
\hline $\operatorname{pvINT}^{U: G}$ & 369 & $335(100 \%)$ & 309 (92 \%) & $16(4.8 \%)$ & $2(0.60 \%)$ & 0 & $1(0.30 \%)$ & $2(0.60 \%)$ & 0 & $3(0.90 \%)$ & $34(8.1 \%)$ & 2 \\
\hline pvINT ${ }^{T: G}$ & 187 & 176 (100 \%) & 77 (44 \%) & $98(56 \%)^{\mathrm{h}}$ & 0 & 0 & 0 & 0 & 0 & 0 & $98(56 \%)$ & 1 \\
\hline $\mathrm{pvINT}^{5 \mathrm{BrU}: \mathrm{G}}$ & 619 & $524(100 \%)$ & 349 (67 \%) & $167(32 \%)^{h}$ & $4(0.76 \%)$ & 0 & $1(0.19 \%)$ & 0 & $2(0.38 \%)$ & $1(0.19 \%)$ & 175 (33 \%) & 2 \\
\hline
\end{tabular}

${ }^{a}$ X:G indicates C:G, 5-mC:G, 5-BrC:G, U:G, T:G, 5-BrU:G mispair

${ }^{\mathrm{b}} \mathrm{A}$ single base substitution, one-base insertion, or one-base deletion detected at the modified base

'One-base deletion

${ }^{\mathrm{d}}$ One-base insertion

'Multiple base substitutions, deletions, and/or insertions detected at sites including the modified base in the BssSI site

${ }^{f}$ Mutations found at sites other than the modified base

${ }^{9}$ Not detectable

${ }^{h} P<0.01$ (significant difference versus pvINT ${ }^{\mathrm{U}: G}$ ) 
finding that the frequency of mutations induced by $5-\mathrm{mC}$ ranges from $10^{-3}$ to $10^{-7}$ in $E$. coli with different genetic backgrounds [10, 22, 31].

Regarding halogenated cytosine, it has been suggested that 5-ClC causes $\mathrm{C}: \mathrm{G}$ to $\mathrm{T}: \mathrm{A}$ transition mutations at rates ranging from 5 to $9 \%$ by mispairing with adenine in $E$. coli [32]. Based on our results, however, 5 - $\mathrm{BrC}$ did not induce C:G to T:A transition mutations (0 \%, Fig. 3 and Table 1). The total proportion of mutants induced by pvINT $^{\text {BrC:G }}(0.71 \%)$ was comparable to that of the control vector. This low pro-mutagenicity of $5-\mathrm{BrC}$ is consistent with an in vitro analysis demonstrating that human DNA polymerases bypass $5-\mathrm{BrC}$ without detectable miscoding [19]. The inconsistency between the previous study on $5-\mathrm{ClC}$ and our results for $5-\mathrm{BrC}$ is probably due to the different atomic radii of the halogens, effects of the specific DNA sequence context, or distinct repair mechanisms between $E$. coli and human cells.

\section{Mutagenic potential of U:G and 5-BrU:G mismatch in the genome}

The integration of pvINT ${ }^{\mathrm{U}: G}$ mainly induced C:G to T:A transition mutations ( $4.8 \%$ ), and the total proportion of mutants was $8.1 \%$ (Fig. 3 and Table 1). This mutagenesis caused by the U:G mismatch in the genome is consistent with that in previous reports describing the well-known pro-mutagenicity of the uracil residue $[4,33]$. Furthermore, the proportion of mutants was dramatically enhanced when pvINT ${ }^{5 B r U: G}$ was integrated $(33 \%)$, resulting in an approximately 7-fold higher proportion of C:G to T:A transition mutations than that occurring when pvINT $^{\mathrm{U}: \mathrm{G}}$ was integrated $(4.8 \%)$ (Fisher's exact test, $P<0.01)$. This indicates that a bromine atom at the $5^{\prime}$-position of uracil interferes with repair using enzymes such as DNA glycosylases in the genome, thereby resulting in enhanced mutagenesis.

\section{Mutagenic potential of T:G mismatch in the genome} Unexpectedly, the integration of the T:G mismatch $\left(\right.$ pvINT $\left.^{\mathrm{T}: \mathrm{G}}\right)$ accounted for the highest proportion of mutants (56 \%) (Table 1). Notably, all these mutants harbored C:G to T:A transition mutations, and the proportion of such mutations was 12-fold higher than that associated with the integration of a U:G mismatch (4.8\%) (Fisher's exact test, $P<0.01$ ) (Fig. 3). This high pro-mutagenicity of $\mathrm{T}$ :G mispairing is in contrasts with a previous report describing that T:G mismatches in episomal DNA are preferentially repaired to $\mathrm{C}: \mathrm{G}$ at an approximate efficiency of $90 \%$ by mismatch repair in mammalian cells [27]. Although our cell lines are mismatch repair proficient [34], the integrated T:G mismatch in the TK locus did not seem to have been corrected. Therefore, the repair efficiency of the T:G mismatch by the specific mismatch repair might depend on the genomic loci where the mismatch has been integrated. Our in vivo results are in agreement with those in a previous in vitro study demonstrating that the repair of mismatched T:G is far less efficient than that of mismatched U:G at a mutational hotspot sequence in the TP53 gene [35].

On the basis of our results, T:G and 5-BrU:G mismatches, resulting from the deamination of 5-mC:G and 5-BrC:G, respectively, markedly enhanced the mutagenic potential compared with that of the U:G mismatch. Although it has been suggested that human thymine DNA glycosylase and methyl-CpG binding protein 4 excise thymine and $5-\mathrm{BrU}$ paired with guanine at $\mathrm{CpG}$ dinucleotides [21, 36-38], they might play minor roles in repair in cells. Thus, once deamination of the modified cytosine occurs, the deaminated residues could steadily induce mutations. Because the frequencies of $\mathrm{C}: \mathrm{G}$ to $\mathrm{T}: \mathrm{A}$ transition mutations induced by $5-\mathrm{mC}$ and $5-\mathrm{BrC}$ were $0.44 \%\left(4.4 \times 10^{-3}\right)$ and $0 \%\left(<10^{-3}\right)$, respectively (Table 1$)$, the frequencies of deamination of them might be equal to or less than the order of $10^{-3}$ in TSCER122 cells. Taking these findings together, we emphasize that those deaminated bases contribute to the mutagenesis and formation of mutational hotspots at specific loci, for example, CpG dinucleotides, in the genome.

\section{Conclusion}

Overall, we revealed the mutagenic potential of modified/deaminated cytosine residues in the human genome. Because T:G and 5-BrU:G mismatches can be highly pro-mutagenic, the rate-limiting step in the formation of mutational hotspots might be the deamination of modified cytosine residues. Our results are also useful to further study the mechanisms by which genomic integrity is maintained.

\section{Abbreviations}

5-BrC: 5-bromocytosine; 5-BrU: 5-bromouracil; 5-ClC: 5-chlorocytosine; 5-mC: 5-methylcytosine; PCR: polymerase chain reaction; TATAM: tracing DNA adducts in targeted mutagenesis; TK: thymidine kinase.

\section{Competing interests}

The authors declare that they have no competing interests.

\section{Authors' contributions}

$A S, Y K, M H$, and MY designed the research and discussed the study. AS, YK, NK, and MY performed the experiments and analyzed the data. AS and MY wrote the paper. All authors read and approved the final manuscript.

\section{Acknowledgements}

We thank Dr. Kenichi Masumura (National Institute of Health Sciences) for helpful discussions and suggestions. We also thank Enago (www.enago.jp) for the English-language review. This research was supported by Grant-in-Aid for Scientific Research (B) from the Ministry of Education, Culture, Sports, Science and Technology and for Health Science Foundation (H27-food-general-002)

from the Ministry of Health, Labor and Welfare in Japan.

\section{Author details}

'Division of Genetics and Mutagenesis, National Institute of Health Sciences, 1-18-1 Kamiyoga, Setagaya-ku, Tokyo 158-8501, Japan. ${ }^{2}$ Present address: Division of Toxicology, Department of Pharmacology, Toxicology and Therapeutics, Showa University School of Pharmacy, Tokyo 142-8555, Japan. 
Received: 13 March 2016 Accepted: 6 May 2016

\section{Published online: 01 September 2016}

\section{References}

1. Vanyushin BF, Tkacheva SG, Belozersky AN. Rare bases in animal DNA. Nature. 1970;225:948-9.

2. Antequera F, Bird A. Number of $C p G$ islands and genes in human and mouse. Proc Natl Acad Sci U S A. 1993;90:11995-9.

3. Bird AP. Gene number, noise reduction and biological complexity. Trends Genet. 1995;11:94-100.

4. Duncan BK, Miller JH. Mutagenic deamination of cytosine residues in DNA. Nature. 1980;287:560-1.

5. Bransteitter R, Pham P, Scharff MD, Goodman MF. Activation-induced cytidine deaminase deaminates deoxycytidine on single-stranded DNA but requires the action of RNase. Proc Natl Acad Sci U S A. 2003;100:4102-7.

6. Morgan HD, Dean W, Coker HA, Reik W, Petersen-Mahrt SK. Activationinduced cytidine deaminase deaminates 5-methylcytosine in DNA and is expressed in pluripotent tissues: implications for epigenetic reprogramming. J Biol Chem. 2004:279:52353-60.

7. Wijesinghe P, Bhagwat AS. Efficient deamination of 5-methylcytosines in DNA by human APOBEC3A, but not by AID or APOBEC3G. Nucleic Acids Res. 2012;40:9206-17.

8. Hollstein M, Sidransky D, Vogelstein B, Harris CC. p53 mutations in human cancers. Science. 1991;253:49-53.

9. Ehrlich M, Norris KF, Wang RY, Kuo KC, Gehrke CW. DNA cytosine methylation and heat-induced deamination. Biosci Rep. 1986;6:387-93.

10. Shen JC, Rideout 3rd WM, Jones PA. The rate of hydrolytic deamination of 5-methylcytosine in double-stranded DNA. Nucleic Acids Res. 1994;22(6):972-6.

11. Weiss SJ, Test ST, Eckmann CM, Roos D, Regiani S. Brominating oxidants generated by human eosinophils. Science. 1986;234:200-3.

12. Harrison JE, Schultz J. Studies on the chlorinating activity of myeloperoxidase. J Biol Chem. 1976;251:1371-4.

13. Foote CS, Goyne TE, Lehrer RI. Assessment of chlorination by human neutrophils. Nature. 1983;301:715-6.

14. Henderson JP, Byun J, Takeshita J, Heinecke JW. Phagocytes produce 5-chlorouracil and 5-bromouracil, two mutagenic products of myeloperoxidase, in human inflammatory tissue. J Biol Chem. 2003;278:23522-8.

15. Henderson JP, Byun J, Williams MV, McCormick ML, Parks WC, Ridnour LA, Heinecke JW. Bromination of deoxycytidine by eosinophil peroxidase: a mechanism for mutagenesis by oxidative damage of nucleotide precursors. Proc Natl Acad Sci U S A. 2001;98:1631-6.

16. Asahi T, Kondo H, Masuda M, Nishino H, Aratani $Y$, Naito $Y$, Yoshikawa T, Hisaka S, Kato Y, Osawa T. Chemical and immunochemical detection of 8-halogenated deoxyguanosines at early stage inflammation. J Biol Chem. 2010;285:9282-91.

17. Shen Z, Mitra SN, Wu W, Chen Y, Yang Y, Qin J, Hazen SL. Eosinophil peroxidase catalyzes bromination of free nucleosides and double-stranded DNA. Biochemistry. 2001;40:2041-51.

18. Masuda M, Suzuki T, Friesen MD, Ravanat JL, Cadet J, Pignatelli B, Nishino H, Ohshima $\mathrm{H}$. Chlorination of guanosine and other nucleosides by hypochlorous acid and myeloperoxidase of activated human neutrophils. catalysis by nicotine and trimethylamine. J Biol Chem. 2001;276:40486-96.

19. Sassa A, Ohta T, Nohmi T, Honma M, Yasui M. Mutational specificities of brominated DNA adducts catalyzed by human DNA polymerases. J Mol Biol. 2011:406:679-86.

20. Sassa A, Kamoshita N, Matsuda T, Ishii Y, Kuraoka I, Nohmi T, Ohta T, Honma M, Yasui M. Miscoding properties of 8-chloro-2'-deoxyguanosine, a hypochlorous acid-induced DNA adduct, catalysed by human DNA polymerases. Mutagenesis. 2013;28:81-8.

21. Valinluck V, Liu P, Kang Jr Jl, Burdzy A, Sowers LC. 5-halogenated pyrimidine lesions within a CpG sequence context mimic 5-methylcytosine by enhancing the binding of the methyl-CpG-binding domain of methyl-CpGbinding protein 2 (MeCP2). Nucleic Acids Res. 2005;33:3057-64.

22. Suspene R, Aynaud MM, Vartanian JP, Wain-Hobson S. Efficient deamination of 5-methylcytidine and 5-substituted cytidine residues in DNA by human APOBEC3A cytidine deaminase. PLoS One. 2013;8:e63461.

23. Coulondre C, Miller JH, Farabaugh PJ, Gilbert W. Molecular basis of base substitution hotspots in Escherichia coli. Nature. 1978;274:775-80.

24. Choi JH, Pfeifer GP. DNA damage and mutations produced by chloroacetaldehyde in a CpG-methylated target gene. Mutat Res. 2004;568:245-56
25. Lee DH, Pfeifer GP. Deamination of 5-methylcytosines within cyclobutane pyrimidine dimers is an important component of UVB mutagenesis. J Biol Chem. 2003;278:10314-21.

26. Kamiya H, Tsuchiya $H$, Karino N, Ueno Y, Matsuda A, Harashima $H$. Mutagenicity of 5-formylcytosine, an oxidation product of 5-methylcytosine, in DNA in mammalian cells. J Biochem. 2002;132:551-5.

27. Brown TC, Jiricny J. A specific mismatch repair event protects mammalian cells from loss of 5-methylcytosine. Cell. 1987;50:945-50.

28. Yasui M, Kanemaru Y, Kamoshita N, Suzuki T, Arakawa T, Honma M. Tracing the fates of site-specifically introduced DNA adducts in the human genome. DNA Repair (Amst). 2014;15:11-20.

29. Arakawa T, Ohta T, Abiko Y, Okayama M, Mizoguchi I, Takuma T. A polymerase chain reaction-based method for constructing a linear vector with site-specific DNA methylation. Anal Biochem. 2011;416:211-7.

30. Sassa A, Kamoshita N, Kanemaru Y, Honma M, Yasui M. Xeroderma pigmentosum group A suppresses mutagenesis caused by clustered oxidative DNA adducts in the human genome. PLoS One. 2015;10:e0142218.

31. Bandaru B, Wyszynski M, Bhagwat AS. Hpall methyltransferase is mutagenic in Escherichia coli. J Bacteriol. 1995;177:2950-2.

32. Fedeles BI, Freudenthal BD, Yau E, Singh V, Chang SC, Li D, Delaney JC, Wilson SH, Essigmann JM. Intrinsic mutagenic properties of 5-chlorocytosine: a mechanistic connection between chronic inflammation and cancer. Proc Natl Acad Sci U S A. 2015;112:E4571-80.

33. Cabral-Neto JB, Gentil A, Cabral RE, Sarasin A. Implication of uracil in spontaneous mutagenesis on a single-stranded shuttle vector replicated in mammalian cells. Mutat Res. 1993:288:249-55.

34. Yamamoto A, Sakamoto Y, Masumura K, Honma M, Nohmi T. Involvement of mismatch repair proteins in adaptive responses induced by $\mathrm{N}$-methyl- $\mathrm{N}^{\prime}$-nitro- $\mathrm{N}$ nitrosoguanidine against gamma-induced genotoxicity in human cells. Mutat Res. 2011;713:56-63.

35. Schmutte C, Yang AS, Beart RW, Jones PA. Base excision repair of U:G mismatches at a mutational hotspot in the p53 gene is more efficient than base excision repair of T:G mismatches in extracts of human colon tumors. Cancer Res. 1995;55:3742-6.

36. Hendrich $\mathrm{B}$, Hardeland $\mathrm{U}, \mathrm{Ng} \mathrm{HH}$, Jiricny J, Bird A. The thymine glycosylase MBD4 can bind to the product of deamination at methylated CPG sites. Nature. 1999;401:301-4.

37. Bennett MT, Rodgers MT, Hebert AS, Ruslander LE, Eisele L, Drohat AC. Specificity of human thymine DNA glycosylase depends on N-glycosidic bond stability. J Am Chem Soc. 2006;128:12510-9.

38. Neddermann P, Gallinari P, Lettieri T, Schmid D, Truong O, Hsuan JJ, Wiebauer K, Jiricny J. Cloning and expression of human G/T mismatchspecific thymine-DNA glycosylase. J Biol Chem. 1996;271:12767-74.

\section{Submit your next manuscript to BioMed Central and we will help you at every step:}

- We accept pre-submission inquiries

- Our selector tool helps you to find the most relevant journal

- We provide round the clock customer support

- Convenient online submission

- Thorough peer review

- Inclusion in PubMed and all major indexing services

- Maximum visibility for your research

Submit your manuscript at www.biomedcentral.com/submit 